\title{
Application of Stochastic Analysis, Modeling and Simulation (SAMS) to Selected Hydrologic Data in the Middle East
}

\author{
Nidhal Saada \\ Civil Engineering Department, \\ Al-Ahliyya Amman University, \\ Amman, Jordan \\ n.saada@ammanu.edu.jo
}

Arwa Hamaideh

Water, Environment and Energy Center,

University of Jordan,

Amman, Jordan

arwa.efb@gmail.com

\author{
Mustafa Abdullah \\ Civil Engineering Department, \\ Al-Ahliyya Amman University, \\ Amman, Jordan \\ mrashied@ammanu.edu.jo

\section{Ali Abu-Romman} \\ Civil Engineering Department, \\ Al-Ahliyya Amman University, \\ Amman, Jordan \\ a.aburuman@ammanu.edu.jo
}

\begin{abstract}
Water resources in the Middle East are very scarce and the management of these resources is a challenge. In this paper, the use of stochastic analysis, modeling, and simulation (SAMS) software package to selected hydrologic data in the Middle East (namely Jordan and Saudi Arabia) are explored. Modeling and simulation experiments were conducted to test the capabilities of SAMS to be used for stochastic modeling and simulation in the Middle East region. The hydrologic data used in this study consist of historic observed rainfall data of different lengths at various sites in Jordan and Saudi Arabia. The models used in this study include: autoregressive moving average (ARMA) models, periodic autoregressive moving average (PARMA) models, multi-site contemporaneous autoregressive moving average (CARMA) models, and temporal disaggregation models. Results indicate that SAMS can be used as a tool for stochastic modeling and simulation of hydrologic data in Jordan and Saudi Arabia. It is important for managers and decision makers of water resources in these countries to be able to use sophisticated tools such as SAMS while deciding water management policies in these countries.
\end{abstract} data

Keywords-stochastic analysis; modeling; simulation; hydrologic

\section{INTRODUCTION}

The region of Middle East suffers from water resource scarcity. The situation is getting worse due to climate change, conflicts, wars, and economic and political instability. As a result, water resource management is a priority for the wellbeing of countries in the region. The use of sophisticated tools for better management of water resources is vital for that region. SAMS is a software package that deals with stochastic analysis, modeling, and simulation of hydrologic time series, and runs under Windows operating system. The package is user friendly and consists of many menu and option windows which enable the user to choose among different available options. The current version of SAMS is SAMS 2007. SAMS capabilities can be classified into three categories: analysis of historic data, model fitting and parameter estimation, and synthetic data generation. The data analysis features of SAMS consist of: data plotting, checking the normality of the data, data transformation, and data statistical characteristics. SAMS has the capability of analyzing single site and multisite annual and seasonal data. The second application of SAMS is model fitting. It includes parameter estimation and model testing for alternative univariate and multivariate annual and monthly stochastic models. These include ARMA, PARMA, multisite ARMA, and disaggregation models [1]. The third main application of SAMS is data generation. Data generation is undertaken based on the fitted models mentioned above. The statistical characteristics of the data are presented in graphical or tabular forms along with the historical statistics of the used data in fitting the models used. In this study, we explore the use of SAMS as a modeling and simulation tool in the Middle East. For that purpose, selected hydrologic data from Jordan and Saudi Arabia were used. Providing water resource managers in the region with powerful modeling and simulation tools is vital for better management of water resources in the region.

\section{METHODOLOGY}

\section{A. Data Used}

The data used in this study consist of the historic monthly and annual rainfall data for two stations in Saudi Arabia (Surat Obeida and Malaki) and the standardized precipitation index (SPI) data for five stations in Jordan (Table I). The data from Surat Obeida covered a period of 30 years from 1981 to 2010 while at Malaki 27 years (1967-1993). The historic monthly rainfall data for the five stations in Jordan were used to 
calculate the SPI [2] for Jordan by using files from the National Drought Mitigation Center.

\section{B. Models Used}

\section{1) ARMA Model}

The $\operatorname{ARMA}(p, q)$ model may be written as [3]:

$$
y_{t}=\sum_{\mathrm{i}=1}^{\mathrm{p}} \phi_{i} y_{t-i}+e_{t}-\sum_{\mathrm{i}=1}^{\mathrm{q}} \theta_{j} e_{t-j}
$$

where $y_{t}$ represents the standardized process for year $t$, it has a mean $=0$ and variance $\sigma_{y}^{2}$ and is normally distributed, $e_{t}$ is the uncorrelated noise term with mean $=0$ and variance $\sigma_{e}^{2}$ and is also normally distributed. $\phi_{1}, \ldots, \phi_{p}$ are the autoregressive parameters; $\theta_{1}, \ldots ., \theta_{q}$ are the moving average parameters. For example, for $p=q=1$, the $\operatorname{ARMA}(1,1)$ model becomes:

$$
y_{t}=\phi_{1} y_{t-1}+e_{t}-\theta_{1} e_{t-1}
$$

TABLE I. DATA USED

\begin{tabular}{|c|c|c|c|c|}
\hline Station Name & Data Type & Period & Length (Y) & Location \\
\hline Malaki & $\begin{array}{c}\text { Annual } \\
\text { Rainfall }\end{array}$ & $1967-1993$ & 27 & Asir, S.A. \\
\hline Surat Obeida & $\begin{array}{c}\text { Monthly } \\
\text { Rainfall }\end{array}$ & $1981-2010$ & 30 & Asir, S.A. \\
\hline Kufr Sawm & SPI & $1983-2013$ & 31 & Irbid, Jordan \\
\hline Ras Munif & SPI & $1983-2013$ & 31 & Irbid, Jordan \\
\hline Jarash & SPI & $1983-2013$ & 31 & Jarash, Jordan \\
\hline Swileh & SPI & $1983-2013$ & 31 & Swileh, Jordan \\
\hline $\begin{array}{c}\text { Amman } \\
\text { Airport }\end{array}$ & SPI & $1983-2013$ & 31 & Amman, Jordan \\
\hline
\end{tabular}

\section{2) PARMA Model}

The $\operatorname{PARMA}(p, q)$ model may be written as [4]:

$$
Y_{v, \tau}=\sum_{\mathrm{i}=1}^{\mathrm{p}} \phi_{i, \tau} Y_{v, \tau-i}+e_{v, \tau}-\sum_{\mathrm{i}=1}^{\mathrm{q}} \theta_{i, \tau} e_{v, \tau-i}
$$

where $Y_{v, \tau}$ represents the standardized process for year $v$ and season $\tau$, it has mean $=0$ and variance $\sigma_{\tau}^{2}(Y)$ and is normally distributed, $e_{v, \tau}$ is the uncorrelated noise term with mean $=0$ and variance $\sigma_{\tau}^{2}(e)$ and is also normally distributed. $\phi_{1, \tau}, \ldots ., \phi_{p, \tau}$ are the seasonal autoregressive parameters; $\theta_{1, \tau}, \ldots ., \theta_{q, \tau}$ are the seasonal moving average parameters. Specifically, for $p=q=1$, the PARMA $(1,1)$ model becomes:

$$
Y_{v, \tau}=\phi_{1, \tau} Y_{v, \tau-1}+e_{v, \tau}-\theta_{1, \tau} e_{v, \tau-1}
$$

\section{3) CARMA Model}

The CARMA model can be decoupled into component univariate models thus making the parameter estimation much easier than the full multivariate models [4]. The CARMA $(p, q)$ model can be described as:

$$
Z_{t}=\sum_{j=1}^{p} \Phi_{j} Z_{t-j}+\varepsilon_{t}-\sum_{j=1}^{q} \Theta_{j} \varepsilon_{t-j}
$$

where $Z_{t}$ is a column vector for year $t$ where each element represents the process (SPI-12 at each site in this case). Each element is normally distributed with mean $=0$ and variance $\sigma_{z}^{2}$. $\Phi_{j}$ are the diagonal autoregressive parameter matrices. $\Theta_{j}$ are the diagonal moving average matrices, $\varepsilon_{t}$ is a vector of residuals of the process at time $t$. They are uncorrelated in time but are correlated in space. Equation (1) can be decoupled and written for each site as:

$$
Z_{t}^{i}=\sum_{j=1}^{p} \phi_{j}^{i} Z_{t-j}^{i}+\varepsilon_{t}^{i}-\sum_{j=1}^{q} \theta_{j}^{i} \varepsilon_{t-j}^{i}
$$

Equation (2) represents the univariate $\operatorname{ARMA}(p, q)$ model for site i. For $p=q=1$, the $\operatorname{ARMA}(1,1)$ model at each site $i$ can then be described as:

$$
Z_{t}^{i}=\phi_{1}^{i} Z_{t-1}^{i}+\varepsilon_{t}^{i}-\theta_{1}^{i} \varepsilon_{t-1}^{i}
$$

The residuals can be expressed as:

$$
\varepsilon_{t}=B \xi_{t}
$$

where $\xi_{t}$ is a vector of random residuals that are uncorrelated in time and in space, and B is a parameter matrix. It can be shown that the covariance matrix of the residuals $\varepsilon_{t}(\mathrm{G})$ can be expressed as [4]:

$$
G=B B^{T}
$$

where $B^{T}$ is the transpose of matrix $B$. As such, the CARMA model implies that the cross-correlations between sites are preserved through the residuals [4]. Notice also that the variances of the residuals $\left(\sigma_{\varepsilon}^{2}\right)$ at each site are the diagonal elements in the $G$ matrix [4] for each corresponding site.

\section{4) Disaggregation Model}

The general Lane's temporal disaggregation model for a number of sites $n$ can be expressed as [5]:

$$
Y_{v, \tau}=A_{\tau} X_{v}+B_{\tau} \varepsilon_{v, \tau}+C_{\tau} Y_{v, \tau-1}
$$

where $Y_{v, \tau}$ is an $n \times 1$ column vector representing the seasonal series, $n$ is the number of sites ( $n=1$ in our case), $X_{v}$ is an $n \times 1$ column vector representing the annual data series, $\varepsilon_{v, \tau}$ is an $(n \times 1)$ vector of uncorrelated normally distributed noise term. The model parameters $A, B$, and $C$ can be estimated using the method of moments [5].

\section{Parameter Estimation}

SAMS has two methods for parameter estimation. These are the method of moments (MOM) and the least squares method (LS). Authors in [1] provided more details about these methods and their calculations by SAMS. Figure 1 shows a screenshot of the SAMS parameter estimation of an $\operatorname{ARMA}(2,1)$ model.

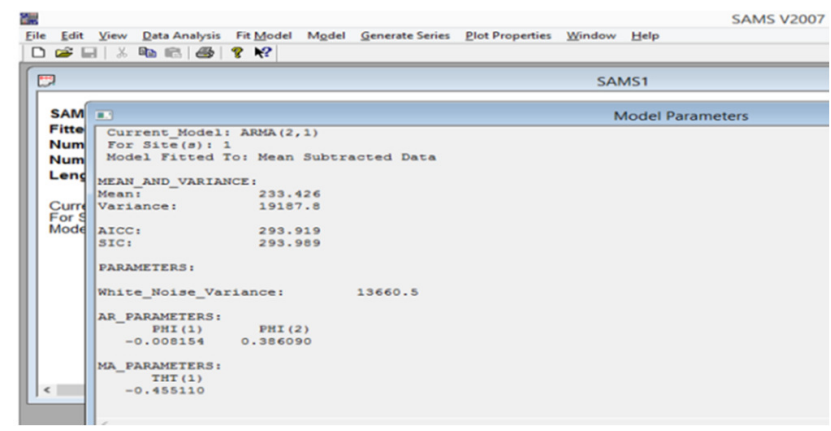

Fig. 1. SAMS parameter estimation for an $\operatorname{ARMA}(2,1)$ model. 
SAMS also provides the user with the ability for the estimation of the PARMA, CARMA, and the disaggregation models.

\section{Stochastic Simulation}

SAMS allows the user to run stochastic simulation experiments. Once the model parameters are estimated, the user can generate synthetic data using the model. A user can specify the number of samples to generate and the length of each sample and SAMS will then generate the required data. Figure 2 shows a screenshot of the SAMS generation of data from an ARMA model. The average statistics calculated from these generated series can then be compared with the historical data statistics. Figure 3 shows such a comparison of the basic statistics such as mean, standard deviation etc. for an $\operatorname{ARMA}(2,1)$ model. Additionally, SAMS provides a statistical comparison for the important drought related statistics such as the longest drough, deficit and surplus statistics, range, and Hurst coefficient as shown in Figure 4. SAMS also provides a statistical comparison for a number of other important statistics such as the correlation structure of the data.

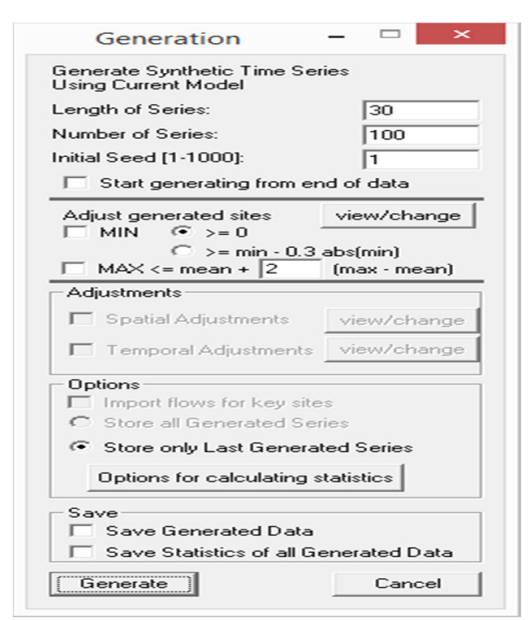

Fig. 2. SAMS data generation window

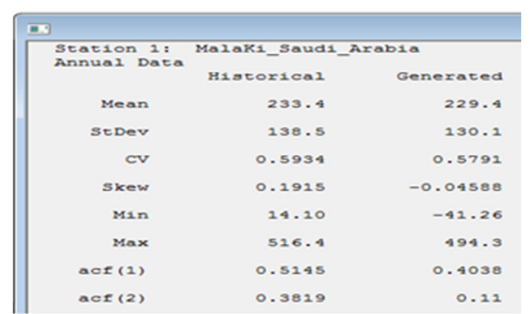

Fig. 3. Comparison between historic and generated basic statistics for an $\operatorname{ARMA}(2,1)$ model

Figure 5 shows a comparison of the serial correlation of the ARMA $(2,1)$ model for Malakai, Saudi Arabia. The ability of a certain model to preserve these statistics is important for water resources managers and decision makers. SAMS gives the managers the ability to try different models in a simple and easy manner.

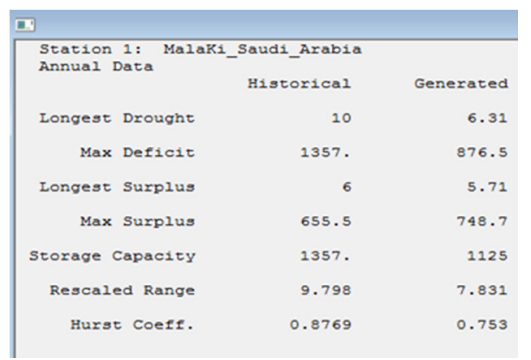

Fig. 4. Comparison between historic and generated drought and surplus related statistics for an $\operatorname{ARMA}(2,1)$ model.

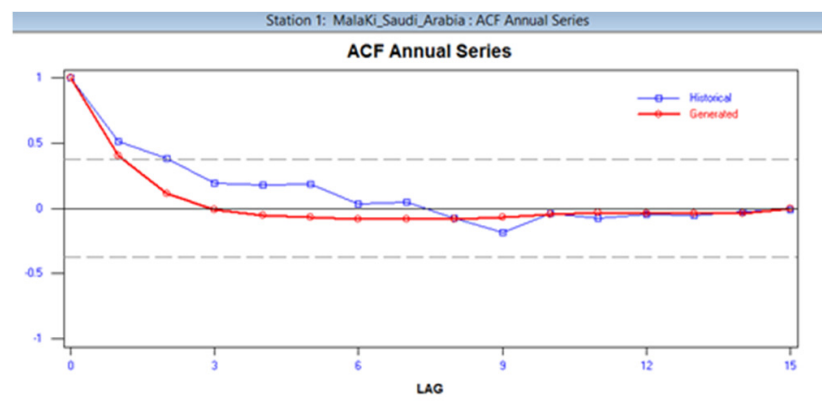

Fig. 5. Comparison between historic and generated serial correlation for an $\operatorname{ARMA}(2,1)$ model.

\section{RESULTS AND DISCUSSION}

SAMS was used to fit several ARMA models to the annual rainfall data at Malakai in Saudi Arabia. Table II shows the parameter estimations for the $\operatorname{ARMA}(1,0), \operatorname{ARMA}(1,1)$, and $\operatorname{ARMA}(2,1)$ models. The results shown are the MOM parameter estimates.

TABLE II. SAMS PARAMETER ESTIMATION OF ARMA MODELS*

\begin{tabular}{|c|c|}
\hline Model & Parameters \\
\hline \multirow{2}{*}{$\operatorname{ARMA}(1,0)$} & Autoregressive parameters: $\phi_{1}=0.514$ \\
& Variance of residuals: $\sigma_{\varepsilon}^{2}=14108.7$ \\
\hline \multirow{3}{*}{$\operatorname{ARMA}(1,1)$} & Autoregressive parameters: $\phi_{1}=0.742$ \\
& Moving average parameters: $\theta_{1}=0.319$ \\
& Variance of residuals: $\sigma_{\varepsilon}^{2}=13711.1$ \\
\hline \multirow{2}{*}{$\operatorname{ARMA}(2,1)$} & Autoregressive parameters: $\phi_{1}=-0.008, \phi_{2}=-0.386$ \\
& Moving average parameters: $\theta_{1}=-0.455$ \\
& Variance of residuals: $\sigma_{\varepsilon}^{2}=13660.5$ \\
\hline
\end{tabular}

* For the annual rainfall at Malakai, Saudi Arabia

Simulations were conducted for Malakai, Saudi Arabia by generating synthetic time series data from the ARMA models mentioned above [6]. In each experiment 100 samples, each with length equal to the historical length of the series at Malakai were generated from the ARMA models [6]. Statistical comparison of historic and generated data revealed that the models were capable of preserving the statistics of historic data such as mean, standard deviation and serial correlation structure [6]. SAMS was also used for modeling and simulation of PARMA models to the monthly rainfall data for Surat Obeida, Saudi Arabia [7]. Similarly, the temporal disaggregation model was also used for modeling and simulation purposes for Surat Obeida, Saudi Arabia [7]. Results indicate that both PARMA and disaggregation model were capable of preserving the seasonal 
statistics of the data [7]. However, the disaggregation model was superior to the PARMA model in terms of preserving the underlying annual correlation structure of the data [7]. Multisite CARMA $(1,1)$ model was applied to the SPI data for the five stations in Jordan [8]. Table III shows the estimated autoregressive and moving average parameters and Table IV shows the estimated variance-covariance matrix of the residuals. Simulation experiments conducted by using the CARMA $(1,1)$ model reveal that the model performed well in preserving the historical statistics of the observed data at each station. Furthermore, the model was able to preserve the spatial cross correlation structure for the stations studied [8]. Table V shows the historical and generated lag-0 cross correlations. Based on the above results, SAMS can provide the user with a very powerfull tool to do sophisticated modeling and simulation of hydrologic data. This is very important for a water resource manager for his/her estimation, prediction and forecasting efforts for better management of water resources.

TABLE III. FITTED CARMA( 1,1$)$ MODEL PARAMETERS FOR SPIDATA IN JORDAN

\begin{tabular}{|c|c|c|}
\hline \multirow{2}{*}{ Station } & \multicolumn{2}{|c|}{ CARMA (1,1) model parameters } \\
\cline { 2 - 3 } & $\begin{array}{c}\text { Autoregressive } \\
\text { parameter }\left(\phi_{1}\right)\end{array}$ & $\begin{array}{c}\text { Moving average } \\
\text { parameter }\left(\boldsymbol{\theta}_{\boldsymbol{I}}\right)\end{array}$ \\
\hline Kufr Sawm & 0.922 & -0.008 \\
\hline Ras Munif & 0.910 & -0.031 \\
\hline Jarash & 0.917 & 0.090 \\
\hline Swileh & 0.938 & 0.082 \\
\hline Amman Airport & 0.895 & -0.006 \\
\hline
\end{tabular}

TABLE IV. RESIDUALS' COVARIANCE MATRIX OF THE FITTED CARMA $(1,1)$ MODEL, SPIDATA, JORDAN

\begin{tabular}{|c|c|c|c|c|c|}
\hline Station & Kufr Sawm & $\begin{array}{c}\text { Ras } \\
\text { Munif }\end{array}$ & Jarash & Swileh & $\begin{array}{c}\text { Amman } \\
\text { Airport }\end{array}$ \\
\hline Kufr Sawm & 0.148 & 0.134 & 0.134 & 0.112 & 0.128 \\
\hline Ras Munif & 0.134 & 0.162 & 0.151 & 0.123 & 0.146 \\
\hline Jarash & 0.134 & 0.151 & 0.188 & 0.124 & 0.169 \\
\hline Swileh & 0.112 & 0.123 & 0.124 & 0.141 & 0.147 \\
\hline Amman Airport & 0.128 & 0.146 & 0.170 & 0.147 & 0.196 \\
\hline
\end{tabular}

TABLE V. HISTORICAL AND GENERATED LAG-0 CORRELATIONS OF THE SPI-12 DATA

\begin{tabular}{|c|c|c|c|c|}
\hline Station & Kufr Sawm & Ras Munif & Jarash & Swileh \\
\hline Kufr Sawm & $1.0(1.0)$ & & & \\
\hline Ras Munif & $0.870 .86)$ & $1.0(1.0)$ & & \\
\hline Jarash & $0.80(0.77)$ & $0.86(0.85)$ & $1.0(1.0)$ & \\
\hline Swileh & $0.77(0.72)$ & $0.80(0.77)$ & $0.75(0.71)$ & $1.0(1.0)$ \\
\hline Amman Airport & $0.75(0.70)$ & $0.82(0.81)$ & $0.88(0.87)$ & $0.85(0.83)$ \\
\hline
\end{tabular}

Generated values in parentheses

\section{CONCLUSION}

SAMS is a software tool that can be used for stochastic modeling and simulation of hydrologic data. Several models were used in this study to fit different stochastic models (ARMA, PARMA, CARMA, and disaggregation models) to hydrologic data in Jordan and Saudi Arabia. Simulation experiments were conducted. Synthetic data were geerated from the different fitted models by SAMS. SAMS provides the user the ability to compare the statistics of the generated data with the historic data. SAMS was proved to be a powerful and valuable tool that can be used by water resource managers in the Middle East and should help them making better decisions in the management of the valuable and scarce water resources in that region.

\section{REFERENCES}

[1] O. G. B. Sveinsson, J. D. Salas, W. L. Lane, D. K. Frevert, Stochastic Analysis, Modeling, and Simulation (SAMS), Version 2007, User's Manual, Colorado State University, 2007

[2] T. B. McKee, N. J. Doesken, J. Kleist, "The Relationship of Drought Frequency and Duration to Time Scales", Eighth Conference of Applied Climatology, Anaheim, USA, January 17-22, 1993

[3] J. D. Salas, N. Saada, C. H. Chung, Stochastic Modeling and Simulation of the Nile River System Monthly Flows, Hydrologic Science and Engineering Program, Department of Civil Engineering, Colorado State University, 1995

[4] J. D. Salas, N. Saada, C. H. Chung, W. L. Lane, D. K. Frevert, Stochastic Analysis, Modeling, and Simulation (SAMS), Version 2000User's Manual, Colorado State University, 2000

[5] W. L. Lane, D. K. Frevert, Applied Stochastic Techniques: (Personal Computer Version): User Manual, Bureau of Reclamation, US Department of Interior, 1990

[6] N. Saada, "Simulation of long term characteristics of annual rainfall in selected areas in Saudi Arabia", Computational Water, Energy, and Environmental Engineering, Vol. 4, No. 2, pp. 18-24, 2015

[7] N. Saada, "Time series modeling of monthly rainfall in arid areas: Case study for Saudi Arabia", American Journal of Environmental Sciences, Vol. 10, No. 3, pp. 277-282, 2014

[8] N. Saada, A. Abu-Romman, "Multi-site modeling and simulation of the standardized precipitation index (SPI) in Jordan", Journal of Hydrology: Regional Studies, Vol. 14, pp. 83-91, 2017 